\title{
Ph and residual gastric volume after mannitol preparation: A randomized controlled study comparing ingestion three versus six hours prior to the procedure
}

Renzo Feitosa Ruiz ${ }^{1 *}$, Jose Jukemura², Paulo Roberto Arruda Alves², Marcos Lera Santos²

'Oswaldo Cruz German Hospital, Treze de Maio st, 1815, Bela Vista, Sao Paulo, zip code 01327, Brazil.

2Department of Gastroenterology of the University of São Paulo School of Medicine, Dr. Arnaldo Av., 455 - Cerqueira César, São Paulo, zip code 01246-903, Brazil.

*Corresponding author: Renzo Feitosa Ruiz, Oswaldo Cruz German Hospital, Treze de Maio st 1815, Bela Vista, Sao Paulo, zip code 01327, Brazil, E-mail: renzofruiz@hotmail.com

Submitted Date: 02 May 2018; Accepted Date: 11 May 2018; Published Date: 14 May 2018

\section{Retraction Note:}

The article entitled " $\mathrm{Ph}$ and residual gastric volume after mannitol preparation: $\mathbf{A}$ randomized controlled study comparing ingestion three versus six hours prior to the procedure," has been accepted for publication in the Clinical Investigation considering the statements provided in the article as personal opinion of the author which was found not having any conflict or biasness towards anything. As the article was a perspective one, information provided by the author was considered as an opinion to be expressed through publication.

Publisher took decision to make the article online solely based on the reviewers suggestion which considered the article not but a personal opinion of the author. However, it is found that the author have some personal concerns and issues, therefore, being retracted from the journal. 